\title{
Spontaneous malignant transformation of a supratentorial pilocytic astrocytoma
}

\author{
A. Otero-Rodríguez; R. Sarabia-Herrero; M. García- Tejeiro* y T. Zamora-Martínez**
}

Servicios de Neurocirugía y de Anatomía Patológica*. Hospital Clínico Universitario. Valladolid. España. Servicio de Anatomía Patológica**. Hospital Universitario Río Hortega. Valladolid. España.

\begin{abstract}
Summary
Pilocytic astrocytoma (PA) is a circumscribed neoplasia considered as a grade $I$ astrocytoma by the World Health Organization. Its most common location is the cerebellum and it develops during the first two decades of the life. Prognosis is mostly excellent if gross-total resection can be achieved, with 10 -year survival rates of up to $80 \%$. Anaplastic or malignant transformation (MT) can rarely occur and is usually related to previous radiation. Spontaneous MT has exceptionally been reported. Histological criteria for diagnosis of MT are unclear, so no consensus exists. We present an atypical case of MT of a frontal PA without previous radiotherapy in a 28 years old patient. Also, we review the literature about prognostic factors of PA and discuss histological features that are considered as anaplastic or malignant in the PA.
\end{abstract}

KEY WORDS: Pilocytic astrocytoma. Malignant transformation. Radiotherapy. Prognosis

Transformación maligna espontánea de un astrocitoma pilocítico supratentorial

\section{Resumen}

El astrocitoma pilocítico es un tumor bien delimitado, que según la clasificación de la Organización Mundial de la Salud, se cataloga dentro del grupo de los astrocitomas de grado I. La localización más frecuente de esta neoplasia es el cerebelo y se manifiesta fundamentalmente en las dos primeras décadas. Siempre y cuando se consiga una resección total, el pronóstico es muy bueno, alcanzando una tasa de supervivencia del $80 \%$ a los diez años. De manera excepcional, puede haber casos de transformación anaplásica o maligna, normalmente asociados a radioterapia previa; se han descrito muy pocas situaciones de transformación

Recibido: 19-11-09. Aceptado: 7-02-10 espontánea. Existe mucha discusión a la hora de considerar los criterios de malignidad desde un punto de vista anatomopatológico. Presentamos un caso excepcional de transformación anaplásica de un astrocitoma pilocítico en un paciente de $\mathbf{2 8}$ años, al igual que revisamos los criterios pronósticos de esta neoplasia y discutimos los datos anatomopatológicos que se consideran de anaplasia 0 malignidad.

PALABRAS CLAVE: Astrocitoma pilocítico. Transformación maligna. Radioterapia. Pronóstico.

\section{Introduction}

Pilocytic astrocytoma (PA) is a slowly growing, relatively circumscribed neoplasia that is classified by the World Health Organization (WHO) as grade I tumour ${ }^{37}$. It usually develops during the first two decades of life and it represents the most common cerebral tumour (18\%) in the paediatric age ${ }^{36}$. PA arises throughout the central nervous system but its most common locations are the cerebellum $(80 \%)$ and hypothalamic/optical pathways ${ }^{12,37}$.

Histologically, PA is characterized by a biphasic pattern: in one, there are compact zones constituted by strongly glial fibrillary acidic protein (GFAP) inmunopositive bipolar cells with Rosenthal fibers, and, on the other, microcystic areas that contain weakly GFAP-positive multipolar cells with eosinophilic granular bodies ${ }^{37}$. Occasional mitoses, hyperchromatic and pleomorphic nuclei and glomeruloid vascular proliferation may appear, but they are not considered signs of malignancy ${ }^{37,47}$. Proliferative markers are generally low, with bromodeoxyuridine (BUdR) index less than $1 \%$ and MIB-1 labelling index ranging from 0 to $3.9 \%{ }^{37}$.

On MRI PA is generally a well-demarcated, either oval or round mass that is constituted by a cyst and mural nodule. Solid component is hipointense relative to gray

Abreviaturas. Cho: choline. GFAP: glial fibrillary acidic protein. MT: malignant transformation. NAA: N-acetylaspartated. PA: pilocytic astrocytoma. WHO: World Health Organization. 
matter in T1-weighted images and hyperintense relative to gray matter in T2-weighted images. After gadolinium administration the mural nodule intensely, heterogeneously enhances $^{25,31}$ while most cyst walls do not ${ }^{25}$. On magnetic resonance spectroscopy, PA has an aggressive-appearing metabolite pattern, with elevated choline (Cho), reduced $\mathrm{N}$-acetylaspartated (NAA), elevated Cho/NAA ratio and high lactate ${ }^{25,31}$.

Overall, prognosis for patients with PA is excellent, with 10 -year survival rate of up $80 \%$ and a 20 -year survival rate of $79 \% \%^{15,25}$. One of the main prognostic factors related to outcome is the degree of resection ${ }^{15,22,40}$. Those tumours undergoing a gross-total resection have a significantly better prognosis than those with subtotal resection ${ }^{15,22,40}$. Radiotherapy has a limited therapeutic role and is indicated when tumours are surgically inaccessible, in multicentric PAs, anaplastic recurrence or significant residual postoperative tumour ${ }^{15,26,40}$.

Sometimes an unfavourable evolution can occur. This feature is characterized by phenomenons such as local recurrence, multicentric disease, leptomeningeal dissemination or malignant transformation (MT) $)^{15,16,40}$. Anaplastic or malignant transformation of PA is a rare event described in the literature ${ }^{12}$. Radiation therapy may be related with this anaplastic change because most of such tumours had been previously irradiated ${ }^{14,33,37}$. However, pathological criteria for classifying PAs with atypical features are unclear $^{33,45}$.

We describe a case of MT of a PA located in frontal lobe without previous radiotherapy. We review the literature about prognostic factors related with PA and the evolution of this tumour. Lastly, we discuss features that are related with anaplastic transformation in PA.

\section{Case report and literature search strategy}

This 25 year old patient was first admitted to our service referring lancinating pain in the left side of his neck for two weeks and double vision on left lateral gaze since 5 days before his admission. He did not refer headache or other neurological symptoms. Neurological examination only evidenced a left VI cranial nerve palsy. Cranial computed tomography and MRI with and without contrast enhancement, showed a voluminous right frontal cystic tumour with nodule and mural enhancement (Figure 1). He was operated through a right pterional approach and complete excision of the tumour was achieved without complications. He was discharged asymptomatic. The tumour was pathologically diagnosed as PA, with some necrotic and brain infiltration areas, but no mitosis nor atypical features were found (Figures 2 and 3).

He was followed on an ambulatory basis for the next 3 years, with no evidence of persistence or recurrence of

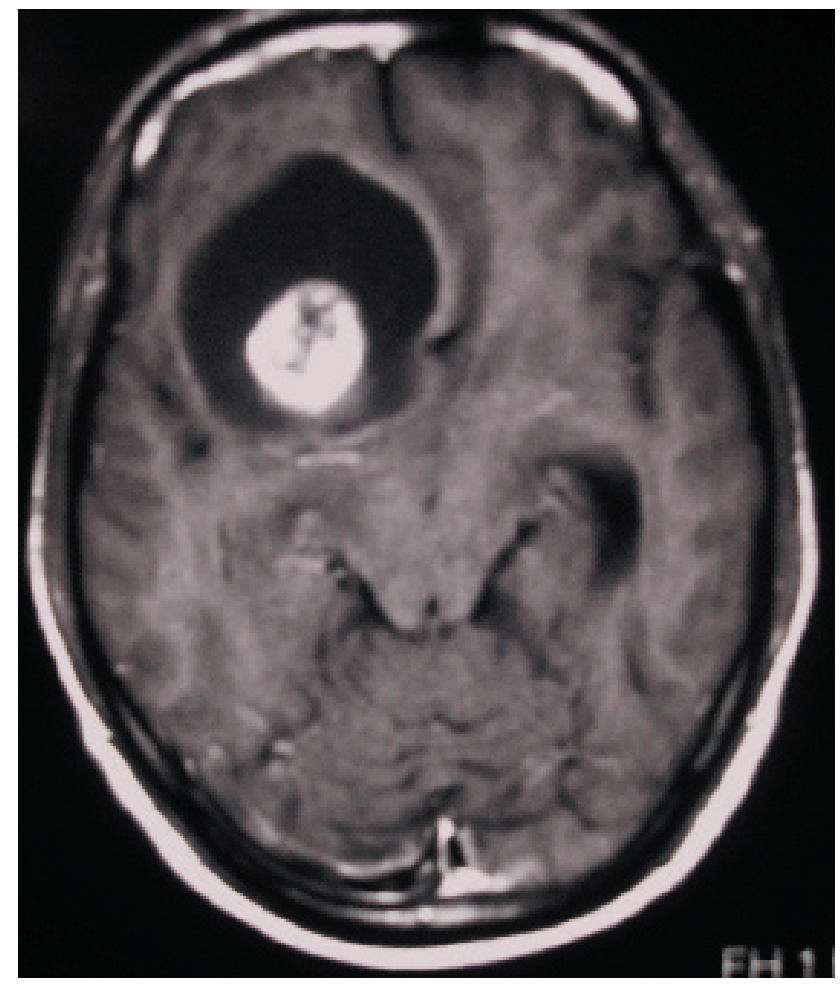

Figure 1. Axial postcontrast MRI showing cystic right frontal tumour with gadolinium enhancing nodule.

the tumour on imaging. 3 years after the operation and 3 months after a normal imaging control study, the patient was readmitted because of an epileptic seizure. The MRI disclosed a rapidly growing recurrent cystic tumour on the right frontal region (Figure 4). He was operated again through the same previous right pterional craniotomy and a complete excision could be achieved although this time, the sylvian artery branches were surrounded and involved by tumour, making resection less straightforward but without complications. The patient was discharged neurologically asymptomatic on anticonvulsants. The pathological diagnosis of the tumour was PA with MT (Figures 5 and 6). He was submitted to the Radiotherapy Service where he was complementary treated with whole brain radiation therapy.

He was followed for the next 30 months, with no remarkable events but some scarce epileptic seizures and imaging studies remained without visible recurrence but some small enhancing punctuate lesions scattered in both cerebral hemispheres and brainstem that progressively appeared and were interpreted as reactive radiotherapy changes.

At this time the patient suffered a new rapid neurological deterioration and was readmitted presenting right hemiplegia and aphasia secondary to a frontoparietal parasagittal subcortical expansive lesion affecting the corpus 


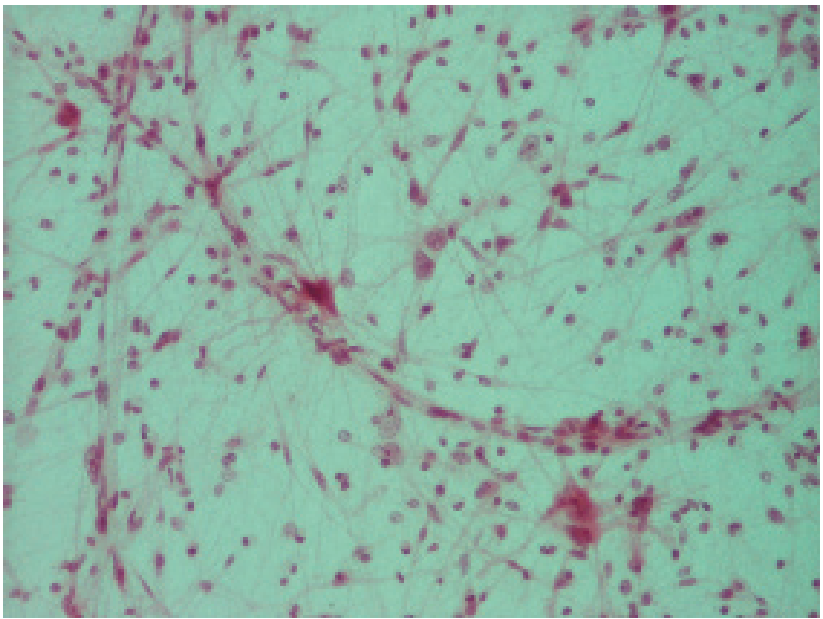

Figure 2. Air dried smears stained with Diff Quick (20x) (Romanowsky type stains). Bipolar neoplastic cells with elongated hair-like processes. The nuclei are round to oval with open chromatin and indistinct nucleoli. Lack of substantial pleomorphysm.

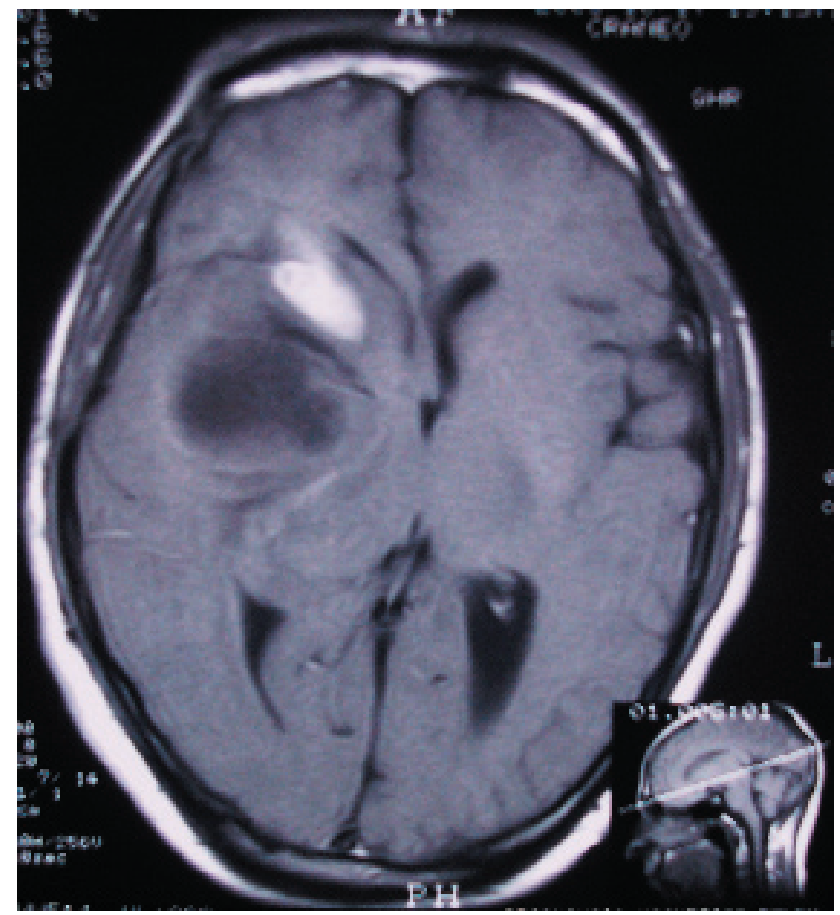

Figure 4. Axial contrast enhanced MRI displays cystic tumor with nodule at the same location.

callosum, which enhanced homogeneously on MRI. The MR spectroscopy was compatible with radionecrosis. No amelioration was obtained with dexamethasone. He was operated through a frontoparietal left craniotomy, excising the necrotic tissue and the pathological diagnosis confirmed radio-necrosis. He recovered partially from his hemiplegia and aphasia, and was discharged with sequelae, that persist

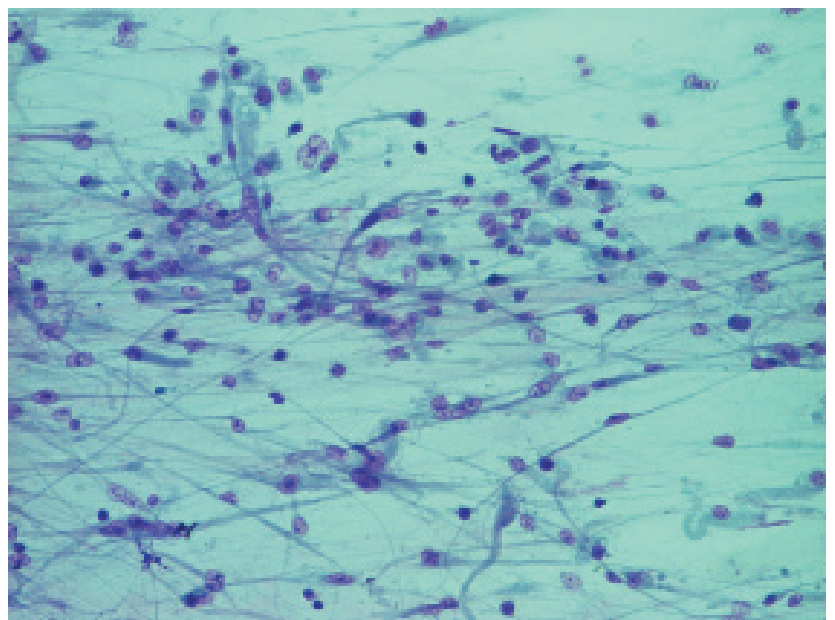

Figure 3. Obtained material smeared on slide, alcoholfixed and stained with Hematoxylin-Eosin (20x). Observe multiple nuclei within large or giant cells. There is no mitosis nor necrosis nor vascular proliferation.

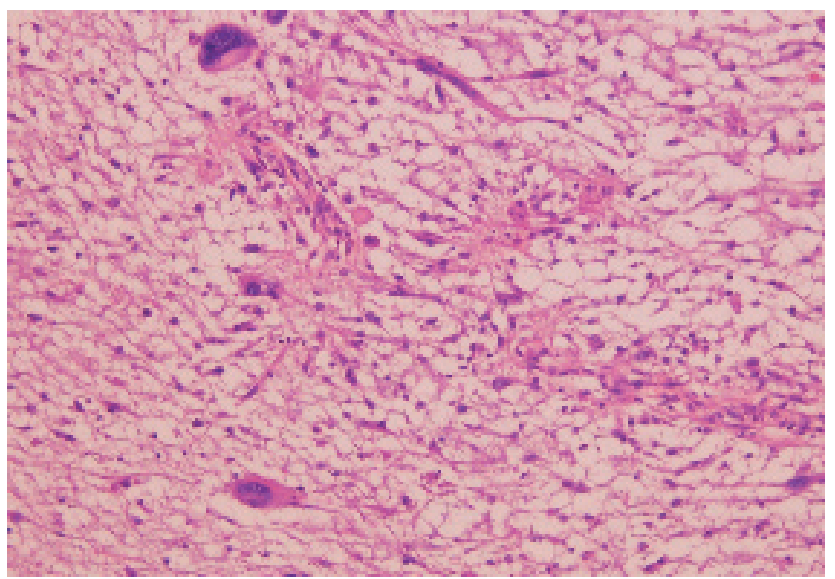

Figure 5. Hematoxylinn-Eosin stained biopsy material (10x) showing malignant degeneration with hypercellularity, higher cellular pleomorphysm and mitotic figures.

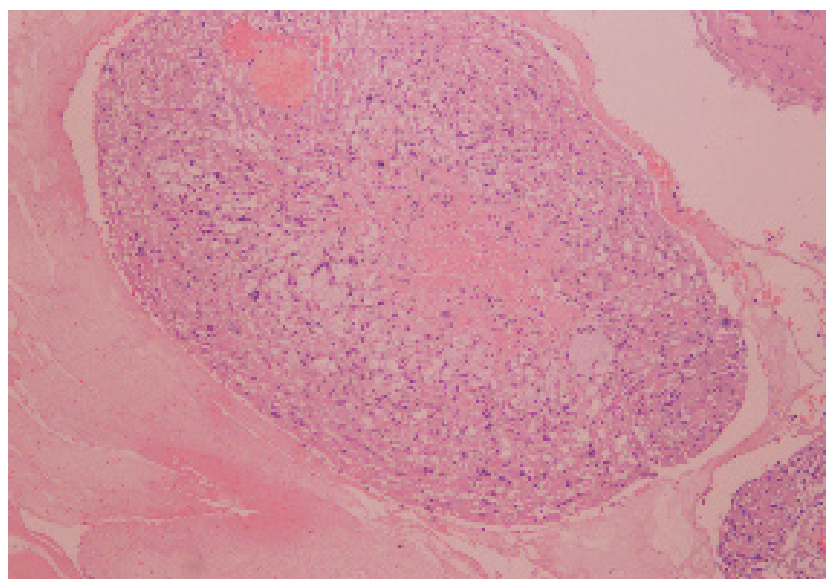

Figure 6. Hematoxylin-Eosin stained biopsy material (20x) of the malignant degeneration tumour showing hypercellularity, endothelial proliferation and focal necrosis. 
2 years after his third operation.

The patient is still alive, 33 years old by now, but neurologically severely disabled. He is ambulatory controlled every 6 months. He developed progressive ventriculomegaly finally requiring a ventriculoperitoneal shunt this year. In the last MR controls no recurrence of the original tumour is seen but there is evidence of leptomeningeal spread of his tumour and a new cerebellar vermian solid tumour that enhances brightly and is compatible with an astrocytic tumour by spectrometry. This tumour has not yet been biopsied.

To review the literature, a computerized search of the National Library of Medicine database of the literature published from 1985 to 2009 was undertaken. The following medical subject headings were used in combination with 'pilocytic astrocytoma': 'anaplastic', 'malignant', 'outcome' and 'prognosis'. Non-English language citations were excluded.

\section{Discussion}

PA is a low-grade, slowly growing tumour, generally considered to have a benign course $\mathrm{e}^{26,37}$. It is classified as a grade I tumour by the WHO grading system, which means a neoplasm with low proliferative potential and the possibility of cure following surgical resection alone ${ }^{37}$. Although PA is regarded as a circumscribed neoplasm, infiltration of the surrounding parenqchyma might be demonstrated histologically $\mathrm{y}^{2,37}$. Coakley et al ${ }^{10}$ observed that $64 \%$ of PAs showed infiltration into the surrounding brain parenchyma at pathological review despite well-demarcated appearance on MRI $(96 \%)$, but the significance of this infiltration is unknown.

The main localizations of PAs are the cerebellum, optic nerve, optic chiasm/hypothalamus, thalamus/basal ganglia and brainstem ${ }^{37}$. Dirven et al ${ }^{12}$ reported that $80 \%$ of PAs have a cerebellar localization. In a retrospective study of 80 cases in paediatric patients ${ }^{15}$, the cerebellum was the most common affected site (33 of 80 PAs), followed by optochiasmatic region $(18 / 80)$ and brainstem $(16 / 80)$. Malik et $\mathrm{al}^{29}$ reported that $61.8 \%$ of 120 PAs included in their study were located in posterior fossa, whereas other affected areas were the supratentorial region (10.8\%), optic nerve (6.7\%), brainstem $(5.8 \%)$ and sellar/suprasellar area (5.8\%). Supratentorial hemispheric PAs, as the presented case in this report, are relatively uncommon and little information has been reported on incidence and behaviour of this location ${ }^{1,5,8,17,18,32}$. In one retrospective, single institution study of 20 recurrent PAs in children, only 3 lesions were described in the cerebral hemispheres ${ }^{3}$. In their series of 107 PAs, Tibbetts et $\mathrm{al}^{45}$ reported that $23 \%(25 / 107)$ of these tumours were located in supratentorial region.
Long-term prognosis for PA is generally considered excellent, with 10-year survival rate of up to $80 \% \%^{5,15,17,22,25}$. In the Childhood Brain Tumour Consortium database, 5-year survival among 481 patients with infratentorial PAs was $95 \%$ over the 50 years of the study ${ }^{21}$. Long-term disease-free survival rates have also been reported. In a retrospective study of $80 \mathrm{PAs}$, the 5-year progression-free survival was $75 \%{ }^{15}$. In a series of one hundred thirty-two astrocytomas of the cerebellum, Hayostek et a ${ }^{22}$ reported that the 5, 10, and 20-year survival rates of the 105 PAs in the series were $85 \%, 81 \%$ and $79 \%$, respectively, and 5year, 10-year, and 20 -year disease-free survival rates were $85 \%, 81 \%$, and $78 \%$. Respect to supratentorial PAs, in a retrospective study about 51 patients, Forsyth et al ${ }^{17}$ reported that survival percentages at 5,10 , and 20 years were $86 \%, 82 \%$, and $82 \%$, respectively. In Brown's cohort of 20 supratentorial PAs in adults, the 5-year progression-free and overall survival rates were both $95 \%$.

Various features have been considered to correlate with prognosis. One of the main prognostic factors is the grade of surgical resection. Complete resection generally implies better prognosis than partial resection. Fernandez ${ }^{15}$ showed that 5-year survival rate was $100 \%$ and $92 \%$ after total and partial removal, respectively. Hayostek found that gross total resection was related with improved survival and disease-free survival ${ }^{22}$. In their study, Forsyth et al ${ }^{17}$ estimated that 10 -year survival percentages were $100 \%$ for the patients who underwent gross total or radical subtotal resection, $84 \%$ for the patients which underwent subtotal resection and $44 \%$ for the patients who underwent biopsy only. In their cohort of 20 supratentorial PAs, Brown et $\mathrm{al}^{5}$ showed that 5-year survival rate was $100 \%$ in the resected group (partial and total resection) and $67 \%$ in the biopsied group. However, in their series of 171 benign cerebellar astrocytomas (pilocytic and nonpilocytic) in children, Pencalet el al ${ }^{34}$ reported that extent of surgical excision was not related with survival, although this feature significantly determined the risk of tumour recurrence. Tumour location also has been related with outcome, but this may be a result of the strong correlation between the extent of resection and tumour location ${ }^{15}$. Fernandez et $\mathrm{al}^{15}$ reported that optochiasmatic PAs carried the worst prognosis (28\% 5-year progression-free survival), and they noted that complete surgical removal was never achieved in this location. The best survival rates were observed in the cerebellum located PAs. Likewise, Tibbetts et $\mathrm{al}^{45}$ found that the optic pathway was the only location statistically associated with worse outcome $(\mathrm{p}=0.0296)$. Pencalet et al showed that if cerebellar PAs extended towards the brainstem ("transitional forms" according to the authors), survival was lower ${ }^{34}$. In their series of ninety-seven patients with cerebellar astrocytomas, Sgouros et $\mathrm{l}^{139}$ concluded that 
Table 1

Spontaneous malignant transformation of pilocytic astrocytoma

\begin{tabular}{lcllc}
\hline Report & $\begin{array}{c}\text { Age at initial } \\
\text { presentation }\end{array}$ & Location & Surgery & $\begin{array}{c}\text { Age at time of } \\
\text { anaplastic change }\end{array}$ \\
\hline Steinberg $^{35}$ & 50 years & Cerebellum & Subtotal resection & 51 years \\
Casadei $^{5}$ & 6 years & Cerebellar hemisphere & Subtotal resection & 41 years \\
Claus $^{6}$ & 41 years & Conus medullaris & Resection & 43 years \\
Krieger $^{21}$ & 3 years & Cerebellar hemisphere & Subtotal resection & 4 years \\
Krieger $^{21}$ & 14 years & Cerebellar hemisphere & Subtotal resection & 14 years 4 months \\
Krieger $^{21}$ & 3 years & IV ventricular floor & Partial resection & 9 years \\
Krieger $^{21}$ & 15 months & Frontoparietal & Subtotal resection & 5 years \\
Stüer* & NA & NA & Total/subtotal & NA \\
Our case & 25 years & Frontal & Total resection & 28 years \\
\hline
\end{tabular}

* 4 cases. Non-described features. NA: not available.

the main negative prognostic factor was the brain stem involvement. There is some controversy over biologic behaviour of PAs in adults. Some authors like Brown et $\mathrm{al}^{45}$ did not find differences in the prognosis of these tumours in adults. However, in reviewing their 44 cases of PAs, Stüer et $\mathrm{al}^{43}$ noted a recurrence rate of $30 \%$ and a MT rate of $50 \%$ for those patients who underwent second surgery for tumour recurrence. Moreover, in the Ellis study of 20 adult patients with PAs found a recurrence rate of $30 \%$ and observed MT in three of the four tumors that required a second resection ${ }^{14}$. Respect to cystic tumours, solid PAs have not been generally associated with shorter survival times ${ }^{15,19,34,42}$. However, Klein et al ${ }^{24}$ observed that cyst-nodule type of PAs were more amenable to total resection because they did not frequently affect the brainstem structures since they usually settled in a lateral cerebellar position.

No association has been generally found between proliferation indices such as MIB-1 labelling or BUdR index and outcome $20,23,28,35,46$. The reported mean values of the MIB-1 labelling range from $0.9 \%$ to $6 \%{ }^{13}$. However, in a report of 39 PAs, Dirven et al ${ }^{13}$ observed that there was a tendency towards fewer tumour progression in the group of PAs with MIB-1 negative indixes than PAs with MIB-1 positive indices $(p=0.15)$. In another report of 141 PAs in children, Bowers et $\mathrm{al}^{4}$ found that a MIB-1 labelling index of more than 2.0 was associated with shortened progression-free survival. Nevertheless, when evaluation of MIB-1 labelling indexes was restricted to partially resected tumours, there was only an insignificant trend of MIB-1 labelling higher than 2.0 having a shortened progression-free survival.
The evolution of patients treated for PAs is occasionally unfavourable since recurrence, LD and MT might occur. Some PAs seed throughout the neural axis. Reported prevalence of $\mathrm{LD}$ ranges from $2 \%$ to $12 \%{ }^{25}$. Incidence of $\mathrm{LD}$ appears increased when PAs are located in the hypothalamus. Mamelak et $\mathrm{al}^{30}$ concluded that hypothalamic PA was 23 times more likely to show dissemination than cerebellar one. This feature might be due to their proximity to the ventricular system. LD tends to occur within 3 years of initial diagnosis. Outcome of patients with LD is unknown ${ }^{16}$. However, this phenomenon does not necessary imply poor prognosis, because of metastatic implants tend to grow slowly ${ }^{37}$.

Anaplastic or malignant transformation is an uncommon event. In the review of Parsa and Givrad ${ }^{33}$, they found 24 reported cases of PA undergoing anaplastic transformation that had been confirmed. They excluded 22 reported tumours initially considered as PAs with MT, because they did not match the criteria for PA. Since most patients with MT of PA had undergone previous radiotherapy and the malignant form developed 5-45 years after the first treatment, radiation therapy might be a factor related with

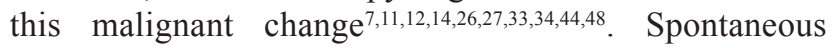
MT has been reported (see Table 1). Tomlinson et $\mathrm{al}^{47}$ estimated that the incidence of spontaneous histological malignancy of PAs was $0.9 \%$ whereas radiation-induced malignancy incidence was $1.8 \%$. However, after a review of these cases, Parsa et $\mathrm{al}^{33}$ think that these tumours might not initially correspond to PA but to diffuse astrocytoma (WHO grade II $)^{7,41}$, reactive piloid gliosis ${ }^{9}$ or pilomyxoid astrocytoma (frontoparietal tumour in Krieger's series) ${ }^{26}$. 
Moreover, anaplasia criteria reported by Krieger et $\mathrm{al}^{26}$ such as increased cellularity and nuclear atypia mismatch with nowadays accepted criteria for anaplasia (see below). Furthermore, Stüer et al describe 4 cases of malignant transformation, but do not specify the location of these tumors ${ }^{43}$. Considering this discussion, we believe that our case is one of the first supratentorial PAs which has undergone MT. As resection was total, we consider MT might have been originated in tumour cells that infiltrate into surrounding brain.

No consensus exists about histological features for diagnosis of anaplastic or malignant variant of $\mathrm{PA}^{27,33}$. Hyperchromasia, nuclear atypia, endothelial proliferation, increased cellularity, mitotic activity, necrosis or multinucleated giant cells have been described as signs of malignancy; however, they have been accepted only by some neuropathologists ${ }^{6,11,26,27,29,33,38,47,49}$. Some features such as hyperchromatic nuclei, multinucleated giant cells and endothelial proliferation are usually considered as degenerative changes ${ }^{26,29}$. Other authors consider that nuclear atypia, increased cellularity, mitotic activity, endothelial activity or necrosis do not correlate with prognosis o have an uncertain prognostic value ${ }^{29,37,47}$. Considering Tomilsen's report ${ }^{47}$, the 2007 WHO classification remarks that PAs which undergo MT often show multiple mitoses per high-power microscopic field, endothelial proliferation and palisading necrosis ${ }^{37}$. Our case shows hypercellularity, necrosis, endothelial proliferation and mitotic figures (Figures 5 and 6), which do not appear in the first description (Figures 2 and 3). Lastly, prognosis of PAs that undergo MT is not necessarily dismal as confirmed by our case. Thus, they must not be designated as multiform glioblastomas ${ }^{37}$.

\section{References}

1. Afra, D., Müller, W., Slowik, F., Firsching, R.: Supratentorial lobar pilocytic astrocytomas: report of 45 operated cases, including 9 recurrences. Acta Neurochir (Wien) 1986; 81: 90-93.

2. Boch, A.L., Cacciola, F., Mokhtari, K., Kujas, M., Philippon, J.: Benign recurrence of a cerebellar pilocytic astrocytoma 45 years after gross total resection. Acta Neurochir (Wien) 2000; 142: 341-346.

3. Bowers, D.C., Krause, T.P., Aronson, L.J., Barzi, A., Burger, P.C., Carson, B.S., Weingart, J.D., Wharam, M.D., Melhem, E.R., Cohen, K.J.: Second surgery for recurrent pilocytic astrocytoma in children. Pediatr Neurosurg 2001; 34: 229-234.

4. Bowers, D.C., Gargan, L., Kapur, P., Reisch, J.S., Mulne, A.F., Shapiro, K.N., Elterman, R.D., Winick, N.J., Margraf, L.R.: Study of the MIB-1 labeling index as a predictor of tumor progression in pilocytic astrocytomas in children and adolescents. J Clin Oncol 2003; 21: 29682973.

5. Brown, P.D., Buckner, J.C., O'Fallon, J.R., Iturria, N.L., Brown, C.A., O'Neill, B.P., Scheithauer, B.W., Dinapoli, R.P., Arusell, R.M., Abrams, R.A., Curran, W.J., Shaw, E.G.: Adult patients with supratentorial pilocytic astrocytomas: a prospective multicenter clinical trial. Int J Radiation Oncol Biol Phys 2004; 58: 1153-1160.

6. Canesso, A., Gardiman, M., Salmaso, R., Alaggio, R., Ninfo, V.: An unusual case of malignant pilocytic astrocytoma occurring in the eye. Virchows Arch 2006; 449: 248-252.

7. Casadei, G.P., Arrigoni, G.L., D'Angelo, V., Bizzozero, L.: Late malignant recurrence of childhood cerebellar astrocytoma. Clin Neuropathol 1990; 9: 295-298.

8. Clark, G.B., Henry, J.M., McKeever, P.E.: Cerebral pilocytic astrocytoma. Cancer 1985; 56: 1128-1133.

9. Claus, D., Sieber, E., Engelhardt, A., Rechlin, T., Neubauer, U., Volk, B.: Ascending central nervous spreading of a spinal astrocytoma. J Neurooncol 1995; 25: 245250 .

10. Coakley, K.J., Huston, J. 3rd, Scheithauer, B.W., Forbes, G., Kelly, P.J.: Pilocytic astrocytomas: well-demarcated magnetic resonance appearance despite frequent infiltration histologically. Mayo Clin Proc 1995; 70: 747-751.

11. Dirks, P., Jay, V., Becker, L., Drake, J.M., Humphreys, R.P., Hoffman, H.J., Rutka, J.T.: Development of anaplastic changes in low-grade astrocytomas of childhood. Neurosurgery $1994 ; 34: 68-78$.

12. Dirven, C.M., Mooij, J.J., Molenaar, W.M.: Cerebellar pilocytic astrocytoma: a treatment protocol based upon analysis of 73 cases and review of the literature. Childs Nerv Syst 1997; 13: 17-23.

13. Dirven, C.M., Koudstaal, J., Jakob, J., Mooij, J.J., Molenaar, W.M.: The proliferative potential of the pilocytic astrocytoma: the relation between MIB-1 labeling and clinical and neuro-radiological follow-up. J Neurooncol 1998; 37: 9-15.

14. Ellis, J.A., Waziri, A., Balmaceda, C., Canoll, P., Bruce, J.N., Sisti, M.B.: J Neurooncol 2009; 95: 377-382.

15. Fernandez, C., Figarella-Branger, D., Girard, N., Bouvier-Labit, C., Gouvernet, J., Paz Paredes, A., Lena, G.: Pilocytic astrocytomas in children: prognostic factors a retrospective study of 80 cases. Neurosurgery 2003; 53: 544-555.

16. Figueiredo, E.G., Matushita, H., Machado, A.G., Plese, J.G., Rosemberg, S., Marino, R. Jr.: Leptomeningeal dissemination of pilocytic astrocytoma at diagnosis in childhood. Two cases report. Arq Neuropsiquiatr 2003; 61 (3B): 842-847.

17. Forsyth, P.A., Shaw, E.G., Scheitauer, B.W., O'Fallon, J.R., Layton, D.D. Jr, Katzmann, J.A.: Supratentorial pilocytic astrocytomas. A clinicopatholo- 
gic, prognostic, and flow cytometric study of 51 patients. Cancer 1993; 72: 1335-1342.

18. Garcia, D.M., Fulling, K.H.: Juvenile pilocytic astrocitoma of the cerebrum in adults: A distinctive neoplasm with favorable prognosis. J Neurosurg 1985; 63: 382-386.

19. Garcia, D.M., Latifi, H.R., Simpson, J.R., Picker, S.: Astrocytomas of the cerebellum in children. J Neurosurg 1989; 71 (5 Pt 1): 661-664.

20. Giannini, C., Scheithauer, B.W., Burger, P.C., Christensen, M.R., Wollan, P.C., Sebo, T.J., Forsyth, P.A., Hayostek, C.J.: Cellular proliferation in pilocytic and diffuse astrocytomas. J Neuropathol Exp Neurol 1999; 58: 46-53.

21. Gilles, F.H., Sobel, E.L., Tavare, C.J., Leviton, A., Hedley-Whyte, E.T.: Age -related changes in diagnoses, histological features, and survival in children with brain tumors: 1930-1979. The Childhood Brain Tumor Consortium. Neurosurgery $1995 ; 37$ : 1056-1068.

22. Hayostek, C.J., Shaw, E.G., Scheithauer, B., O'Fallon, J.R., Weiland, T.L., Schomberg, P.J., Kelly, P.J., Hu, T.C.: Astrocytomas of the cerebellum. A comparative clinicopathologic study of pilocytic and diffuse astrocytomas. Cancer 1993; 72: 856-869.

23. Ito, S., Hoshino, T., Shibuya, M.: Proliferative characteristics of juvenile pilocytic astrocytomas determined by bromodeoxyuridine labeling. Neurosurgery 1992; 31: 413-419.

24. Klein, D.M., McCullough, D.C.: Surgical staging of cerebellar astrocytomas in childhood. Cancer 1985; 56 (7 Suppl): 1810-1811.

25. Koeller, K.K., Rushing, E.J.: Pilocytic astrocytoma: radiologic-pathologic correlation. Radiographics 2004; 24: 1693-1708.

26. Krieger, M.D., Gonzalez-Gomez, L., Levy, M.L., McComb, J.G.: Recurrence patterns and anaplastic change in a long-term study of pilocytic astrocytomas. Pediatr Neurosurg 1997; 27: 1-11.

27. Lach, B., Al Shail, E., Patay, Z.: Spontaneous anaplasia in pilocytic astrocytoma of cerebellum. Br J Neurosurg 2003; 17: $250-252$.

28. Machen, S.K., Prayson, R.A.: Cyclin D1 and MIB-1 inmunohistochemistry in pilocytic astrocytomas: a study of 48 cases. Hum Pathol 1998; 29: 1511-1516.

29. Malik, A., Deb, P., Sharma, M.C., Sarkar, C.: Neuropathological spectrum of pilocytic astrocytoma-an Indian series of 120 cases. Pathol Oncol Res 2006; 12: 164-171.

30. Mamelak, A.N., Prados, M.D., Obana, W.G., Cogen, P.H., Edwards, M.S.B.: Treatment options and prognosis for multicentric juvenile pilocytic astrocytoma. J Neurosurg 1994; 81: 24-30.

31. Osborn, A.G. et al.: Pilocytic astrocytoma. In: Osborn AG (eds) Diagnostic Imaging: Brain, 1st edn. Salt Lake City,
Utah. Amirsys. 2004; I6: pp 30-33.

32. Palma, L., Guidetti, B.: Cystic pilocytic astrocytomas of the cerebral hemispheres: Surgical experience with 51 cases and long-term results. J Neurosurg 1985; 62: 811815.

33. Parsa, C.F., Givrad, S.: Juvenile pilocytic astrocytomas do not undergo spontaneous malignant transformation: grounds for designation as hamartomas. $\mathrm{Br} \mathrm{J}$ Ophthalmol 2008; 92: 40-46.

34. Pencalet, P., Maixner, W., Sainte-Rose, C., Lellouch-Tubiana, A., Cinalli, G., Zerah, M., Pierre-Kahn, A., Hoppe-Hirsch, E., Bourgeois, M., Renier, D.: Benign cerebellar astrocytomas in children. J Neurosurg 1999; 90: 265273.

35. Roessler, K., Bertalanffy, A., Jezan, H., Ba-Ssalamah, A., Slave, I., Czech, T., Budka, H.: Proliferative activity as measured by MIB-1 labeling index and long-term outcome of cerebellar juvenile pilocytic astrocytomas. J Neurooncol 2002; 58: 141-146.

36. Rosemberg, S., Fujiwara, D.: Epidemiology of pediatric tumors of the nervous system according to the WHO 2000 classification: a report of 1,195 cases from a single institution. Childs Nerv Syst 2005; 21: 940-944.

37. Scheithauer, B.W., Hawkins, C., Tihan, T., VandenBerg, S.R., Burger, P.C.: Pilocytic astrocytoma. In: Louis DN, Ohgaki H, Wiestler OD, Cavenee WK (eds) WHO Classification of Tumours of the Central Nervous System, 4th edn. Lyon, France. IARC Press. 2007; pp 14-21.

38. Schwartz, A.M., Ghatak, N.R.: Malignant transformation of benign cerebellar astrocytoma. Cancer 1990; 65: 333336.

39. Sgouros, S., Fineron, P.W., Hockley, A.D.: Cerebellar astrocytoma of childhood: long-term follow-up. Childs Nerv Syst 1995; 11: 89-96.

40. Smith, E.R., Ebb, D.H., Tarbell, N.J., Barker, II F.G.: Pilocytic astrocytoma. In: Berger MS, Prados MD (eds) Textbook of Neuro-Oncology, 1st edn. Philadelphia, Pennsylvania, United States. Saunders. 2005; pp 149-155.

41. Steinberg, G.K., Shuer, L.M., Conley, F.K., Hanberry, J.W.: Evolution and outcome in malignant astroglial neoplasms of the cerebellum. J Neurosurg 1985; 62: 9-17.

42. Strong, J.A., Hatten, H.P. Jr, Brown, M.T., Debatin, J.F., Friedman, H.S., Oakes, W.J., Tien, R.: Pilocytic astrocytoma: correlation between the initial imaging features and clinical aggressiveness. AJR Am J Roentgenol 1993; 161: 369-372.

43. Stüer, C., Vilz, B., Majores, M., Becker, A., Schramm, J., Simon, M.: Frequent recurrence and progression in pilocytic astrocytoma in adults. Cancer 2007; 110 : 2799-2808.

44. Tamura, M., Zama, A., Kurihara, H., Fujimaki, H., Imai, H., Kano, T., Saitoh, F.: Management of recurrent pilocytic astrocytoma with leptomeningeal dissemination in 
childhood. Childs Nerv Syst 1998; 14: 617-622.

45. Tibbetts, K.M., Emnett, R.J., Gao, F., Perry, A., Gutmann, D.H., Leonard, J.R.: Histopathologic predictors of pilocytic astrocytoma event-free survival. Acta Neuropathol 2009; 117: 657-665.

46. Tihan, T., Davis, R., Elowitz, E., DiCostanzo, D., Moll, U.: Practical value of Ki-67 and p53 labeling indexes in stereotactic biopsies of diffuse and pilocytic astrocytomas. Arch Pathol Lab Med 2000; 124: 108-113.

47. Tomilson, F.H., Scheithauer, B.W., Hayostek, C.J., Parisi, J.E., Meyer, F.B., Shaw, E.G., Weiland, T.L., Katzmann, J.A., Jack, C.R. Jr.: The significance of atypia and histologic malignancy in pilocytic astrocytoma of the cerebellum: a clinicopathologic and flow cytometric study. J Child Neurol 1994; 9: 301-310.

48. Van der Wal, E.P.J., Azzarelli, B., Edwards-Brown,
M.: Malignant transformation of a chiasmatic pilocytic astrocytoma in a patient with diencephalic syndrome. Pediatr Radiol 2003; 33: 207-210.

49. Wallner, K.E., Gonzales, M.F., Edwards, M.S.B., Wara, W.M., Sheline, G.E.: Treatment results of juvenile pilocytic astrocytoma. J Neurosurg 1988; 69: 171-176.

Otero-Rodríguez, A,; Sarabia-Herrero, R.; García- Tejeiro, M.; Zamora-Martínez, T.: Spontaneous malignant transformation of a supratentorial pilocytic astrocytoma. Neurocirugía 2010; 21: 245-252.

Adress: Álvaro Otero Rodríguez. Servicio de Neurocirugía. Complejo Asistencial Universitario de Salamanca. Paseo de San Vicente, 58-182. 37008, Salamanca, España e-mail: alvarotero_es@hotmail.com 